IBIMA Publishing

International Journal of Veterinary Medicine: Research \& Reports

http://www.ibimapublishing.com/journals/IJVMR/ijvmr.html

Vol. 2014 (2014), Article ID 162176, 10 pages

DOI: $10.5171 / 2014.162176$

Research Article

\title{
Successful Postnatal Care of a Premature Orphan Foal Delivered by Caesarean Section
}

\author{
Zsófia Bohák ${ }^{1}$, Orsolya Kutasi ${ }^{1}$, Sára Sárdi ${ }^{2}$, Letícia Moravszki ${ }^{2}$ and Ottó Szenci ${ }^{3}$ \\ ${ }^{1}$ Szent István University, Faculty of Veterinary Science, Equine Department and Clinic, Üllő, Dóra \\ major, Hungary; HAS-SZIU Large Animal Clinical Research Group, Üllő, Hungary \\ ${ }^{2}$ Szent István University, Faculty of Veterinary Science, Equine Department and Clinic, Üllő, Dóra \\ major, Hungary \\ ${ }^{3}$ Szent István University, Faculty of Veterinary Science, HAS-SZIU Large Animal Clinical Research \\ Group, Üllő, Hungary
}

Correspondence should be addressed to: Zsófia Bohák; bohak.zsofia@aotk.szie.hu

Received 17 September 2013; Accepted 15 November2013; Published 25 December 2013

Academic Editor: Gerald Fritz Schusser

Copyright @ 2014 Zsófia Bohák, Orsolya Kutasi, Sára Sárdi, Letícia Moravszki and Ottó Szenci. Distributed under Creative Commons CC-BY 3.0

\begin{abstract}
A 9-year-old Shagya Arabian pregnant mare showing signs of acute colic, underwent exploratory laparotomy at our clinic. Owing to the discovery of an inoperable leiomyoma in the abdominal cavity, the animal was euthanized. The 305-day-old fetus, which showed signs of prematurity was removed by Caesarean section and resuscitated. Clinicopathologic examination revealed a low neutrophil:lymphocyte ratio. Radiographic evaluation of the carpus and tarsus was performed and showed grade 3 ossification according to the Adams-Poulos Grading System.
\end{abstract}

The immature gastrointestinal tract was unable to digest enteral feeding; this led to the development of enterocolitis and septicemia. Thrombophlebitis developed at the site of the long-acting intravenous catheter and methicillin-resistant Staphylococcus aureus was isolated from the exudate. The guttural pouches were empyematous. Follow-up radiographic examinations indicated improvement in bone maturation.

The foal was discharged in a good state of health 35 days postnatum, and apart from an easily managed respiratory tract infection, no further problems were reported.

Keywords: Prematurity, equine neonate, septic foal, postnatal care.

\section{Introduction}

Equine prematurity is difficult to define because of differences between breeds and other influencing factors (the fetal gender, etc.). Nevertheless, according to current knowledge premature foals born after less than 280 days of gestation almost never survive and even foals delivered at 300 days tend not to be viable. The survival rate after 320 days of gestation is more satisfactory [10]. When predicting chances

Cite this Article as: Zsófia Bohák, Orsolya Kutasi, Sára Sárdi, Letícia Moravszki and Ottó Szenci (2014), "Successful Postnatal Care of a Premature Orphan Foal Delivered by Caesarean Section," International Journal of Veterinary Medicine: Research \& Reports, Vol. 2014 (2014), Article ID 162176, DOI: $10.5171 / 2014.162176$ 
of survival, it is also important to consider whether the delivery occurred spontaneously or the foal was born as a result of Caesarean section owing to a sudden illness or injury to the mare. Premature foals born spontaneously as a result of chronic stress have better survival rates than foals delivered by Caesarean section at the same gestational age $[24,25,26]$. While the development of the fetal pituitary adrenal axis is dependent on cortisol, during the majority of gestation, the fetus is not exposed to high levels of cortisol. Fetal cortisol production increases significantly during the final 24-48 h before parturition, presumably as a result of increased adrenal 17 $\alpha$-hydroxylase activity. This period of cortisol exposure is essential for the final maturation of the fetal pituitary adrenal axis and the respiratory system [34]. Consequently, if spontaneous delivery is brought on by chronic stress (e.g., because of placentitis, as the result of twinning, or congenital problems associated with the placenta or the foal) and stress-associated-cortisol release occurs in the mare, the foal may still undergo the necessary cortisol-related maturation to prepare it for the extrauterine environment $[10,33]$.

Even when born at term, the rearing of a newborn foal poses a special challenge and if it is compounded by a mare's death, it may further reduce the chances of the foal's survival [14].

\section{Case History and Clinical Findings}

A Shagya Arabian mare was presented for acute colic at the Clinic for Large Animals (presently Equine Department and Clinic) in Üllő, Hungary. The 9-year-old mare weighed $445 \mathrm{~kg}$ and was in advanced pregnancy (gestational length: 305 days). During exploratory laparotomy, the premature foal was delivered by Caesarean section. The mare was euthanized during surgery because of the presence of an inoperable tumor in the abdominal cavity (Fig. 1). The weight of the tumor was $40 \mathrm{~kg}$, and histological examination revealed it to be a leiomyoma.

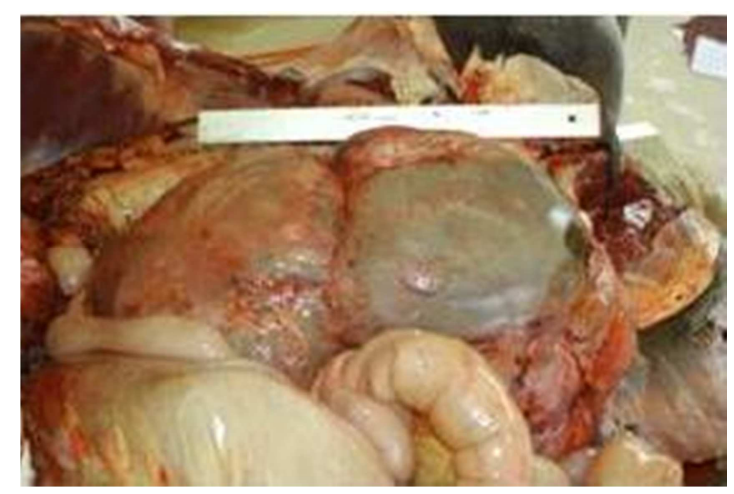

Fig. 1. Inoperable Leiomyoma in the Abdominal Cavity of the Dam

The newborn filly showed signs of prematurity: underweight $(30 \mathrm{~kg})$ (the average weight of a newborn foal is $50 \mathrm{~kg}$ ) [26] with pliant ears, soft lips, entropion, weak musculature, and poor suckling reflex. The foal was unconscious and unresponsive, and respiration was irregular and infrequent. The peripheral pulse was almost absent and heart rate was low (40 bpm) [10]. Mydriasis was observed in both eyes and capillary refill time was prolonged. Clinicopathological examination revealed a low neutrophil:lymphocyte ratio and the white blood cell count was also low. The blood lactate and creatinine levels were elevated, and the packed cell volume (PCV) was also high. Although there was no immediate possibility to measure IgG level, the serum globulin level was low. The foal had mild hypoglycemia, which persisted and occasionally worsened over the first few days post-partum. Urine output was low. 
Radiographic evaluation of the carpus and tarsus was performed to assess the degree of ossification. The degree of incomplete ossification in the cuboidal bones was assessed as being grade 3 according to the Adams-Poulos grading system [1] (Fig. 2).

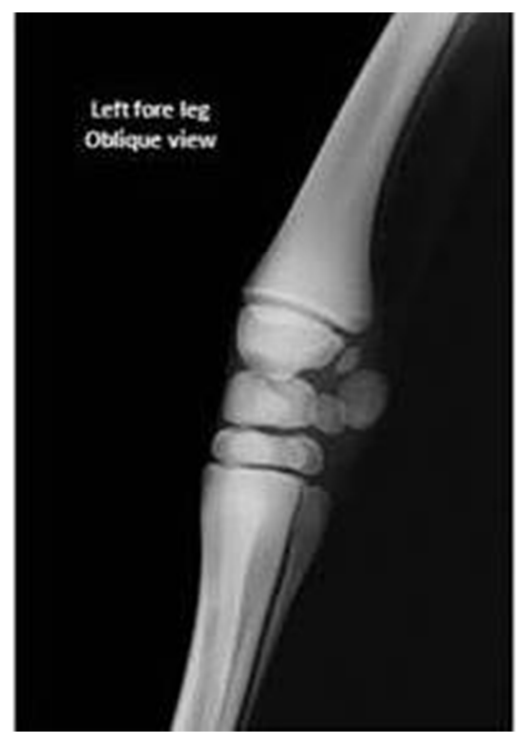

Fig. 2. Radiographic Appearance of the Premature Carpus

\section{Treatments}

On the basis of these results and observations, resuscitation was performed immediately after birth [11]. The high creatinine level can reflect not only hypovolaemia in newborn foals, but also can be caused by other abnormal conditions, e.g. by in utero placental dysfunction. Increased PCV is also not solely indicative of hypovolemia [8], but based on the history, laboratory findings and clinical signs, emergency fluid resuscitation was initiated. A bolus of half of the shock dose rate $(60 \mathrm{~mL} / \mathrm{kg})$ of balanced electrolyte solution (Lactated Ringer's Solution, "Baxter" 1000 mL) ${ }^{1}$ was administered rapidly, and the foal was reassessed: Basic clinical parameters were within normal limits (HR, 86 bpm; RR, $46 / \mathrm{min}$; and $\mathrm{T}, 37.4^{\circ} \mathrm{C}$ [under the infrared light]), the pulse was strong, and mentation was improved. To provide for maintenance requirements and ongoing losses, fluid therapy was continued at a rate of $5 \mathbf{~ m L} / \mathbf{k g}^{-\mathbf{h}}{ }^{-1}$. For short-term nutritional support $30 \mathrm{~mL}$ of $40 \%$ Glucose (Glucose $40 \%$ inf. $500 \mathrm{~mL})^{2}$ and $30 \mathrm{~mL}$ of a vitamin and electrolyte solution (Duphalyte ${ }^{\circledR}$ injection A.U.V.) ${ }^{3}$ were added to each liter of crystalloid infusion [8]. As part of our intensive care strategy antimicrobial therapy with ceftriaxon (Rocephin, 25 $\mathrm{mg} / \mathrm{kg}$ i.v. b.i.d.) ${ }^{4}$ was started immediately after birth.

Because of the absence of suckling reflex, a permanent nasogastric tube (Salem Sump tube GS4018) ${ }^{6}$ was placed and $1 \mathrm{~L}$ of stored colostrum was administered in 4 portions over the first $8 \mathrm{~h}$. Frozen colostrum was used from mares at the clinic. Despite not knowing the IgG level of the foal, $3 \mathrm{~L}$ of plasma supplementation was also administered (20 $\left.\mathbf{m L} / \mathbf{k g} \cdot \mathbf{h}^{-\mathbf{1}}\right)$ to support immune function. After the supplementation, plasma total protein and the globulin level were $63.4 \mathrm{~g} / \mathrm{L}$ and 35.3 $\mathrm{g} / \mathrm{L}$, respectively, suggesting that an adequate humoral immune status had been achieved [23]. Over the same period, the blood glucose level decreased in spite of the recommended amounts of good quality colostrum being fed. (Table 1.)

The foal did not pass meconium in the first $36 \mathrm{~h}$, and subsequent treatment with an acetylcysteine retention enema was successful. Because of the risk of corneal ulceration from the congenital entropion 
[3], the in-turning eyelids were corrected surgically.

Biochemistry performed 2 days after delivery showed a low neutrophil count, marked hypoglycemia, arterial hypoxaemia, and metabolic acidosis. Clinical examination at this point showed the foal to be hyperthermic, depressed, and diarrheic. According to the Foal Sepsis Score Sheet, the foal had a total of 23 points, which is predictive of sepsis in 93\% of the time [4,7,13]. Thoracic and abdominal radiography showed increased pulmonary interstitial pattern, and distended intestines which were also visible on ultrasound. Observation of comet-tail echoes and inflammatory areas on ultrasonographic examination of the lungs confirmed the presence of pneumonia. When enterocolitis developed, total parenteral nutrition with appropriate amino acid, lipid, and vitamin content was considered but not administered owing to financial limitations. During the period of diarrhea nutrition was provided both parenterally and peroral. The maintenance fluid requirement $\left(100 \mathrm{~mL} / \mathrm{kg} \cdot\right.$ day $\left.^{-1}\right)$ was supplemented with Glucose (Glucose 40\% inf. $500 \mathrm{~mL})^{2}$ and a vitamin and electrolyte solution (Duphalyte ${ }^{\circledR}$ injection A.U.V.) ${ }^{3}$. The reduced oral nutrition consisted of overly diluted milk replacer (Salvana Fohlenmilch) $)^{5}$ and the concentration was increased as the foal accepted more intensive peroral feeding. The foal was initially fed every hour and then gradually less frequently as larger volumes could be given [10]. In spite of regular feeding and parenteral energy supplementation, the foal had extremely high hypertriglyceridemia $(9.2 \mathrm{mmol} / \mathrm{L})$. In addition to the glucose infusion, recombinant human regular insulin (Actrapid Penfill) 6 was administered by continuous rate infusion (dose rates ranged between 0.0016 and $0.018 \mathrm{IU} / \mathrm{kg} \cdot \mathbf{h}^{-1}$ ) $[22,29]$. Blood glucose level was regularly checked. When the foal was able to utilize a sufficient amount of orally administered feed (as seen by increased blood glucose and reduced triglyceride levels), intravenous fluid and energy supplementation were discontinued.

Non-steroidal anti-inflammatory drugs (Neoprofen $10 \%$ inj., $2.2 \mathrm{mg} / \mathrm{kg}$ i.v. s.i.d.) ${ }^{7}$ [2] were administered during the period of diarrhea and, in order to safeguard against possible side effects, renal function was monitored and proton pump inhibitors were given (Omeprazole, $4 \mathrm{mg} / \mathrm{kg}$ p.o. s.i.d. $)^{8}$. With the exception of the first 2 days after delivery, the levels of creatinine and BUN were within the normal ranges. Despite a negative blood culture the spectrum of antimicrobial therapy was extended with penicillin (Tardomyocel comp. III susp., $3 \mathrm{~mL} / 50 \mathrm{~kg}$ i.m. s.i.d.) ${ }^{9}$, metronidazole (Klion, $25 \mathrm{mg} / \mathrm{kg}$ p.o. b.i.d.) ${ }^{10}$ and amikacin (Likacin inj., $25 \mathrm{mg} / \mathrm{kg}$ i.v. s.i.d.) ${ }^{11}$ [9]. A probiotic preparation (ProPaste for horses, $2 \mathrm{~mL} /$ foal, p.o. b.i.d. $)^{12}$ was also administered.

Treatments were supplemented with kaolin bolus (Bolus adstringens, 1 tablet $/ 10 \mathrm{~kg}$ p.o. b.i.d.) ${ }^{13}$, Psyllium (Sand Clear, 1 scoop/day, p.o. b.i.d.) ${ }^{14}$, activated carbon (Carbo Activatus $500 \mathrm{~g})^{15}$ and paraffin oil (Mol White Oil M 46) ${ }^{16}$ and diarrhea was solved. In addition to the antimicrobial therapy, the lower airways were supported with Vitamin C (Acidum ascorbicum) ${ }^{15}$ and bromhexine (Bisolvon, $0.25 \mathrm{~g} / 10 \mathrm{~kg}$ p.o. b.i.d. $)^{17}$. 
Table 1. Clinicopathological Data of the Foal Pre-, during and after Treatment

\begin{tabular}{|c|c|c|c|c|c|c|c|c|c|c|c|c|}
\hline AGE (day) & $\mathbf{0}$ & 1 & 1 (afternoon) & 2 & 5 & 8 & 11 & 15 & 18 & 21 & 25 & 32 \\
\hline $\mathrm{WBC}\left(\mathrm{x}^{10} 0^{9} / \mathrm{L}\right)$ & 4.28 & 3.07 & 1.77 & 3.72 & 33.3 & 10.00 & 24.6 & 28.3 & 8.97 & 7.79 & 9.55 & 7.90 \\
\hline N:L & 0.28 & 0.78 & 0.84 & 6.76 & 9.56 & 5.7 & 27.58 & 12.78 & 3.47 & 1.49 & 1.72 & 1.73 \\
\hline Albumin (g/L) & 27.83 & & 28.71 & & & 25.98 & 23.23 & 23.86 & 22.37 & 23.59 & 25.61 & 23.90 \\
\hline Total protein $(\mathrm{g} / \mathrm{L}$ & 42.00 & & 63.40 & & & 50.30 & 46.30 & 49.70 & 52.30 & 57.20 & 48.60 & 49.80 \\
\hline Globulin (g/L) & 11.36 & & 35.30 & & & 24.32 & 20.36 & 22.05 & 29.93 & 32.61 & 19.93 & 25.90 \\
\hline Glucose $(\mathrm{mmol} / \mathrm{L})$ & 3.12 & 2.30 & 1.59 & 2.21 & & 8.43 & 10.43 & 8.06 & 6.46 & 7.70 & 4.61 & 7.53 \\
\hline Tryglicerid (mmol & 3.28 & 4.40 & 7.76 & 9.20 & & 2.45 & 0.59 & 1.27 & 0.48 & 0.68 & 0.91 & 0.82 \\
\hline Lactate $(\mathrm{mmol} / \mathrm{L})$ & 13.55 & & 3.34 & 10.84 & & 3.37 & 2.29 & 1.44 & 2.31 & 1.65 & 1.39 & 2.06 \\
\hline BUN (mmol/L) & 11.10 & & 10.60 & & & 3.80 & 1.90 & & & 1.50 & 2.30 & 1.60 \\
\hline Creatinin $(\mu \mathrm{mol} / \mathrm{L}$ & 225.00 & & 198.20 & & & 72.00 & 74.20 & & & 79.00 & 80.00 & 81.00 \\
\hline pH & & 7.26 & & 7.27 & 7.27 & 7.30 & & & & & & 7.37 \\
\hline $\mathrm{p}_{\mathrm{a}} \mathrm{CO}_{2}(\mathrm{mmHg})$ & & 52.80 & & 51.10 & 45.30 & 44.60 & & & & & & 44.20 \\
\hline $\mathrm{p}_{\mathrm{a}} \mathrm{O}_{2}(\mathrm{mmHg})$ & & 60.00 & & 64.00 & 77.00 & 79.90 & & & & & & 94.00 \\
\hline $\mathrm{HCO}^{3-}(\mathrm{mmol} / \mathrm{L})$ & & 22.70 & & 23.10 & 24.70 & 25.50 & & & & & & 31.10 \\
\hline
\end{tabular}

The foal was recumbent and depressed during the first week and was first able to stand without assistance 10 days after delivery. The follow-up radiographic assessment of the limbs and cuboidal bones showed at that time improvement in terms of ossification. Exercise was gradually increased as the foal became stronger [16]. Strengthening of the soft tissues of the limbs was supported by the use of bandaging and splinting on all 4 legs. This limb support was removed for part of each day (about $12 \mathrm{~h} /$ day) to allow for loading of the tendons and the periarticular softtissue structures.

Recurrent mild impaction, which resulted in abdominal distention, was presumed to be caused by the immaturity of the gastrointestinal tract. It was treated using prokinetics such as metoclopramide (Cerucal inj., $0.05 \mathrm{mg} / \mathrm{kg}$ i.m.) ${ }^{18}$ and neostigmine (Konstigmin inj., 0.0044 $\mathrm{mg} / \mathrm{kg} \mathrm{s.c.)}{ }^{19}$ [31], and also seemed to be alleviated when the foal was encouraged to move.

Despite using a long-acting intravenous catheter (Equivet HiFlow LongTerm IV Catheter $14 \mathrm{G} \times 3.5 \mathrm{~cm}$, Langeskov,
Denmark) ${ }^{20}$ and antibiotics, thrombophlebitis developed at 2 weeks of age. The foal became recumbent, hyperthermic, and developed severe tachycardia. The left jugular vein was warm and appeared painful, and a small amount of purulent discharge was present at the site of the intravenous catheter from which methicillin resistant Staphylococcus aureus was isolated. Both guttural pouches were empyematous. Over this period, in order to overcome the multiple bacterial resistances antibiotic treatment was changed to a combination of erythromycin (Meromycin, $37.5 \mathrm{mg} / \mathrm{kg}$ p.o. b.i.d.) ${ }^{21}$ and rifampicin (Rifamed, 5-10 mg/kg p.o. s.i.d.) ${ }^{22}$ [22]. To prevent transmission to other animals the foal was isolated and was handled by only a small number of people. Precautionary measures were used to minimize pathogen spread and avoid zoonotic transmission [27]. Aggressive wound cleaning was maintained until the infection resolved and the wound healed. The guttural pouches were flushed with sterile fluids endoscopically twice a day until there was no discharge.

One week later, the results of physical examination and clinicopathological 
findings were within normal limits. The antimicrobial and supportive treatments were continued for a further 7 days after which only probiotic therapy was continued. The nasogastric tube was removed at this time and the foal was trained to drink from a bucket.

\section{Outcome}

Thirty-five days after delivery, the foal was discharged in a good state of health to the Babolna National Stud farm. The stud farm veterinary surgeon reported that the foal, aged 1.5 years at the time of writing, had suffered a respiratory tract infection 3 months after discharge which was treated successfully, and has since displayed no other health issues.

\section{Discussion}

In order to assess the level of prematurity and the presence and degree of failure of passive transfer (FPT) an adrenocorticotropic hormone (ACTH) stimulation test, and cortisol- and IgG level determination should be performed shortly after birth. In premature foals, FPT cannot only be the result of inadequate colostrum intake, but can also reflect gastrointestinal absorption abnormalities. That a combination of these factors was involved in the development of FPT in this case is supported by the lack of increase in blood glucose after peroral colostrum feeding. Plasma globulin status was improved when, in addition to the recommended volume of colostrum, the foal also received plasma supplementation. In this case, use of the ACTH stimulation test to determine the degree of prematurity was unnecessary, as this was apparent from the physical appearance as well as knowledge of the gestational age of the foal.

Caesarean section has been associated with neonate immaturity because of the absence of the pre-parturient endogenous steroid release. It is debated as to whether the use of corticosteroids in premature foals is beneficial as these immunosuppressant agents have been shown to have a harmful effect on the immune system of equine neonates [20]. However, the immunosuppressive activity is predominantly restricted to cell-mediated immunity, with only a minimal inhibitory effect on humoral immunity. The real immunologic and clinical effects of a hydrocortisone therapy are still not clear [17] and this treatment was, therefore, not used in this case. It is possible that the presence of the abdominal tumor was a source of chronic stress for the mare and the fetus which could have resulted in untimely endogenous steroid release. The Adams-Poulos Grade 3 ossification of the cuboidal bones was higher than could be expected at 305 days of gestation. However, the intestinal dysfunction, and the external appearance of the foal were suggestive of prematurity, the foal was probably more developed than a normal 305-day-old fetus. However it was still considered to be premature.

The prematurity-related intestinal dysfunction and absorption deficiency that represented the major problems during the first 2 weeks of life were compounded by the development of septicaemia and enterocolitis. It is not clear whether the FPT led to sepsis and subsequent enterocolitis or whether enterocolitis, caused by enteral feeding of the immature gastrointestinal tract, led to the development of septicaemia as a result of the excessive translocation of bacteria across the gut. Besides these eventualities hypoxemia, and consequent tissue hypoxia, gastroduodenal ulceration, lactose intolerance, infections (e.g. Clostridium difficile) or other factors may have played also a role in the apparent diarrhoea. Some of these possibilities were unlikely, since the foal had normal faeces several times between the period of meconium impaction and diarrhoea. Clostridium infection was also not expected, because the occurrence of $\mathrm{Cl}$. difficile caused enterocolitis is very uncommon in Hungary. The presence of gastroduodenal ulceration could not be ruled out, but Omeprazole was administered.

Conflicting opinions arose in connection with the administration of Omeprazole. Javsicas and Sanches (2010) [21] investigated the effect of Omeprazole (4 
$\mathrm{mg} / \mathrm{kg}$ p.o.) on intragastric $\mathrm{pH}$ in critically ill neonates. The intragastric $\mathrm{pH}$ was significantly higher in the post treatment period compared to the pretreatment period. Furr et al. (2012) [12] evaluated the influence of anti-ulcer medications on the development of undifferentiated or infection caused diarrhea in compromised neonatal foals. The importance of gastric acidity in protecting against bacterial translocation was also investigated. In the examined 1102 foals the occurrence of diarrhea was significantly higher with the use of any anti-ulcer medication, including sucralfate treatment. However the study was designed retrospectively and the influence of the different hospitals, clinicians and the original disease of the foals may not have been completely eliminated [12]. In this premature case, the used nonsteroidal anti-inflammatory drug (ketoprofen) was a nonselective cyclooxygenase (COX) inhibitor; therefore the synthesis of prostaglandins was also inhibited. Besides this and the possible perinatal transient tissue hypoxia, $\mathrm{pH}$ dependent gastric ulceration also had to be taken into account.

The use of nonsteroidal anti-inflammatory drugs in critically ill neonates raises many issues and it is a frequently studied topic also in equine and in human medicine [5, 28, 30]. Morris et al. [28] discussed the importance of the prostaglandin system in the healthy development of human neonates. In this study the role of selective cyclo-oxygenase type 2 (COX-2) inhibitors arose especially in connection with the gastrointestinal adverse effects. However it was also emphasized, that the possibility of investigations in this topic is still far from being exhausted [28]. Several years later, Raidal et al. [30] tested the use of meloxicam $(0.6 \mathrm{mg} / \mathrm{kg}$; p.o.) in foals less than 6 weeks of age. No threatening side effects were revealed even at higher dose (1.8 mg/kg; p.o.) of administration. Nevertheless only healthy foals were used in the experiment, hence the extrapolation of these results to compromised neonates requires special caution [30]. These data [30] were not available at the time of the admission of the presented foal, but the main advantages of the relatively COX-2 selective meloxicam were already known. Using a nonselective COX inhibitor (ketoprofen) was a necessary decision in this case, since selective COX-2 inhibitor was not available in Hungary.

Glucose infusions, given for the apparently impaired gastrointestinal absorption, are probably only suitable for $12-24 \mathrm{~h}$ of nutritional support when not combined with lipid and protein supplementation [10]. The preterm gut is very sensitive to enteral feeding which may either promote gut adaptation and health, or induce gut dysfunction, bacterial overgrowth and inflammation. The interaction between gut bacteria and host tissue in a newborn compromised intestine has been studied in many species, especially in infants and piglets. Enteral feeding induced bacterial colonization stimulates structural, functional and immunological maturation of the intestinal tissue [19]. Nevertheless, enteral feeding has been associated with necrotizing enterocolitis (NEC) in preterm piglets [32]. The effect of minimal enteral nutrition combined with parenteral nutrition was evaluated by Cilieborg et al. [6] in piglets. Minimal enteral colostrum feeding improved intestinal structure, function, and NEC resistance. For this reasons, despite the risk of excessive bacterial translocation across the immature gut, oral feed intake was given at a reduced rate and not completely withdrawn.

The presence of sepsis, combined with the impaired absorption resulted in an inadequate nutritional status, and extremely high triglyceride levels. Hypertriglyceridemia has been associated with many complications in septic human patients, including immunosuppression, increased production of inflammatory mediators (such as interleukins), lipid intolerance, allergic reactions, thrombocytopenia, cholestasis, increased parameters in liver function tests and fat embolism, the latter occurring especially in premature neonates $[15,18]$. The complications seen in this case were not attributed to the high triglyceride level, but probably also delayed the healing process. 
It is important to note that handling of a premature foal is almost the most important factor in the later clinical history. For this reason a good knowledge of the availability of equipment and medication is necessary to allow rapid decision making. Delay in the treatment of the compromised neonate is an important risk factor contributing to poor survival rate [25]. For example, without financial constraints, it may have been possible to avoid the development of hypertriglyceridemia in this case with adequate parenteral nutrition. Accordingly, the planning of the intensive care of a premature, orphan foal should start with consideration of both the economic benefits and responsibilities arising from each clinical decision as considerable financial resources may be necessary to achieve a favorable outcome. With respect to the equine neonate, welfare of the patient, the end use of the animal, and the emotional and financial considerations of the owner might be the overriding these concerns.

\section{Acknowledgements}

The authors thank Dr. Mónika Kulik for referring the case to the former Clinic for Large Animals, Dr. Simon Izing and their colleges, for performing the caesarean section surgery, Dr. Zita Makra for the ophthalmological interventions and Dr. Imre Biksi for the histological examinations. Further we would like to thank the then fourth-year students (Emese Bódai, Ágnes Povázsai) for their technical assistance.

\section{Manufacturers}

1. Baxter Hungary Ltd., Budapest, Hungary

2. TEVA Pharmaceutical cPlc, Debrecen, Hungary

3. Fort Dodge Veterinaria, S.A., Vall de Bianya, Spain

4. Roche, Budaörs, Hungary

5. Salvana Tiernahrung GmbH, Elmshorn, Germany
6. Novo Nordisc A/S, Chartres, France

7. Kela N.V., Hoogstraten, Belgium

8. Ratiopharm Hungaria, Budapest, Hungary

9. Bayer Hungaria, Budapest, Hungary

10. Richter Gedeon Plc, Budapest, Hungary

11.Lisapharma s.p.a., Erba, Italy

12.Protexin veterinary, Probiotics International Ltd, Somerset, United Kingdom,

13.EGIS, Budapest, Hungary

14.Farnam Companies, Osborn, USA

15.Hungaropharma cPlc, Budapest, Hungary

16.MOL-LUB Ltd., Almásfüzítő, Hungary

17. Boehringer Ingelheim Vetmedica $\mathrm{GmbH}$, Ingelheim, Germany

18.AWD Pharma, Radebeul, Germany

19.Vetoquinol, Paris, France

20.Joergen Kruuse, Langeskov, Denmark

21.Pannon Pharma, Pécsvárad, Hungary

\section{References}

1. Adams, R. \& Poulos, P. (1988). "A Skeletal Ossification Index for Neonatal Foals," Veterinary Radiology, (29) 21722.

2. Aiello, S. E. \& Mays, A. (1998). The Merck Veterinary Manual, 8th Ed. Merck and Company, Inc. Whitehouse Station, NJ.

3. Barr, S. B. et al. (2009). 'Foal Care,' Equine Manual for Veterinary Technicians, Blackwell Publishing Ltd, Singapore. 
4. Brewer, B. D. \& Koterba. A. M. (1988). "Development of a Scoring System for the Early Diagnosis of Equine Neonatal Sepsis," Equine Veterinary Journal, (20) 18-22.

5. Carrick, J. B., Papich, M. G., Middleton D. $M$. et al. (1989). "Clinical and Pathological Effects of Flunixin Meglumine Administration to Neonatal Foals," Canadian Journal of Veterinary Research, (53) 195-201.

6. Cilieborg, M. S., Boye, M., Thymann, T., Jensen, B. B. \& Sangild, P. T. (2011). "Diet-Dependent Effects of Minimal Enteral Nutrition on Intestinal Function and Necrotizing Enterocolitis in Preterm Pigs," JPEN. Journal of Parenteral and Enteral Nutrition, (1) 32-42.

7. Corley, K. T. T. \& Furr, M. O. (2003). "Evaluation of a Score Designed to Predict Sepsis in Foals," Journal of Veterinary Emergency and Critical Care, (13) 149-55.

8. Corley, K. T. T. (2008). 'Fluid Therapy,' The Equine Hospital Manual, Blackwell Publishing Ltd, Oxford.

9. Corley, K. T. T. \& Hollis, A. R. (2009). "Antimicrobial Therapy in Neonatal Foals," Equine Veterinary Education, (21) 436-48.

10. Corley, K. T. T. (2009). 'Other Foal Diseases,' Conference Proceedings of XVII. Annular Seminar, Equine Neonatology, Brno; 55-68.

11. Fielding, C. L. \& Magdesian, K. G. (2003). "Cardiopulmonary Cerebral Resuscitation in Neonatal Foals," Clinical Techniques in Equine Practice, (2) 9-19.

12. Furr, M., Cohen, N. D., Axon, J. E., Sanchez, L. C., Pantaleon, L., Haggett, E., Campbell, R. \& Tennent-Brown, B. (2012). "Treatment with HistamineType 2 Receptor Antagonists and Omeprazole Increase the Risk of Diarrhoea in Neonatal Foals Treated in
Intensive Care Units," Equine Veterinary Journal, (41) 80-6.

13. Furr, M. (2003). "Systemic Inflammatory Response Syndrome, Sepsis, and Antimicrobial Therapy," Clinical Techniques in Equine Practice, (2) 3-8.

14. Grogan, E. H. \& Mcdonnell, S. M. (2005). "Mare and Foal Bonding and Problems," Clinical Techniques in Equine Practice, (4) 228-237.

15. Gugliemli, F. W., Boggio-Bertinet, D., Federico, A. et al. (2006). "Total Parenteral Nutrition-Related Gastroenterological Complications," Digestive and Liver Disease, (38) 62342.

16. Hardy, J. \& Latimer, F. (2003). "Orthopedic Disorders in the Neonatal Foal," Clinical Techniques in Equine Practice, (2) 96-119.

17. Hart, K. A., Barton, M. H., Vanderplas, M. L. \& Hurley, D. J. (2011). "Effects of Low-Dose Hydrocortisone Therapy on Immune Function in Neonatal Horses," Pediatric Research, (70) 72-7.

18. Heyland, D. K., Macdonald, S., Keefe, L. \& Drover, J. W. (1998). "Total Parenteral Nutrition in the Critically Ill Patient: A Meta-Analysis," JAMA : the Journal of the American Medical Association, (280) 2013-9.

19. Hooper, L. V., Falk, P. G. \& Gordon, J. I. (2003). "Analyzing the Molecular Foundations of Commensalism in the Mouse Intestine," Current Opinion in Microbiology, (3) 79-85.

20. Horohov, D. \& Gluck, M. H. (2005). "Maturation of the Neonate's Immune Response," Journal of Equine Veterinary Science, (25) 366.

21. Javsicas, L. H. \& Sanches, L. C. (2008). "The Effect of Omeprazole Paste on Intragastric Ph in Clinically Ill Neonatal Foals," Equine Veterinary Journal, (40) 41-4. 
22. Knottenbelt, D. C. (2004). 'Drug Names and Dosages for Foals,' Equine Neonatology Medicine and Surgery. 1st Ed, W.B. Saunders, Philadelphia.

23. Koterba, A. M., Brewer, B. D. \& Tarplee, F. A. (1984). "Clinical and Clinicopathological Characteristics of the Septicemic Neonatal Foal: Review of 38 Cases," Equine Veterinary Journal, (16) 376-383.

24. Koterba, A. (1990). 'Prematurity,' Equine Clinical Neonatology, Lea \& Febiger, Philadelphia.

25. Koterba, A. \& House, J. (1996). 'Prematurity,' Large Animal Internal Medicine, CV Mosby Inc, Philadelphia.

26. Lester, G. D. (2003). 'Prematurity,' Current Therapy in Equine Medicine. 5th Edn., WB Saunders, Philadelphia

27. Magdesian, K. G. (2008). 'Methicillin Resistant Staphylococcus Aureus,' Journal of Equine Veterinary Science, (28) 608-609.

28. Morris, J. L., Rosen, D. A. \& Rosen, K. R. (2003). "Nonsteroidal AntiInflammatory Agents in Neonates," Pediatric Drugs, (6) 385-405.

29. Myers, Ch. J. \& Magdesian, K. G. (2009). "Parenteral Nutrition in Neonatal Foals: Clinical Description, Complications and Outcome in 53 Foals [1995-2005]," The Veterinary Journal, (181) 137-144.

30. Raidal, S. L., Edwards, S., Pippia, J., Boston, R. \& Noble, G. K. (2013). "Pharmacokinetics and Safety of Oral Administration of Meloxicam to Foals," Journal of Veterinary Internal Medicine, (27) 300-7.

31. Rowe, E. (2008). 'Management of Horses with Gastrointestinal Disorders,' The Equine Hospital Manual, Blackwell Publishing Ltd, Oxford.
32. Sangild, P. T., Siggers, R. H., Schmidt, M. et al. (2006). "A Diet- and ColonizationDependent Intestinal Dysfunction Predisposes to Necrotizing Enterocolitis (NEC) in Preterm Pigs," Gastroenterology (130) 2776-2792.

33. Sangild, P. T. (2003). "Uptake of Colostral Immunoglobulins by the Compromised Newborn Farm Animal," Acta veterinaria Scandinavica. Supplementum, (98) 105-122.

34. Silver, M., Fowden, A. L., Knox, J., Ousey, J., Cash, R. \& Rossdale, P. D. (1991). "Relationship between Circulating TriIodothyronine and Cortisol in the Perinatal Period in the Foal," Journal of Reproduction and Fertility. Supplement, (44) 619-26. 